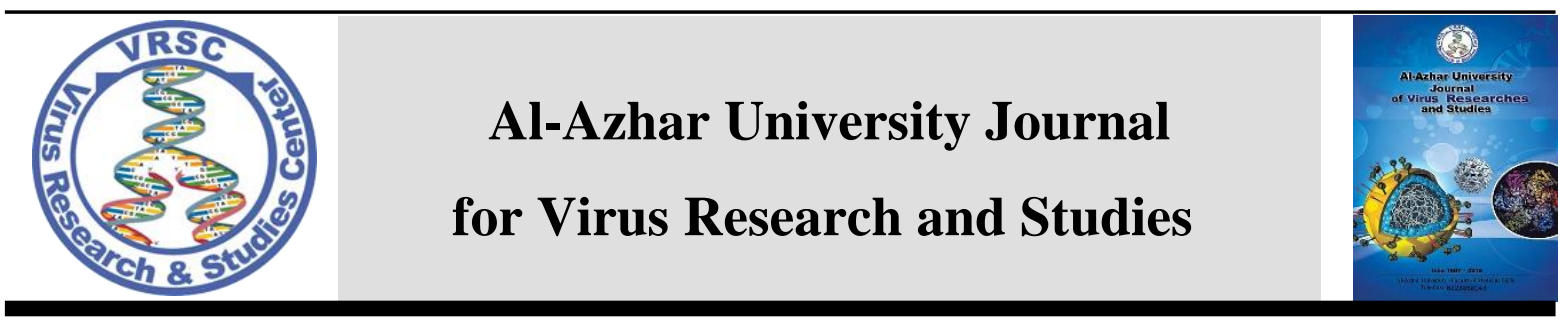

\title{
Role of Zidovudine and Candesartan combination in novel SARS- CoV-2 management, prophylaxis and treatment trials
}

\author{
Mohamed A. Mostafa* \\ Faculty of Pharmacy, Mansoura University, Dakahleya, Egypt \\ E-mail: sahhaa@hotmail.com
}

\begin{abstract}
The coronavirus disease 19 (COVID-19) is a highly communicable and pathogenic viral infection caused by severe acute respiratory syndrome coronavirus 2 (SARS-CoV-2), which raised in Wuhan, China and stretch around the humankind. Genomic analysis exposed that SARS-CoV-2 is phylogenetically associated to severe acute respiratory syndrome-like (SARSlike) bat viruses, hence bats could be the possible primary reservoir. The intermediate obtain of beginning and relocation to humans is not known, however, the rapid human to human transfer has been confirmed commonly. There is no clinically approved antiviral drug or vaccine available to be used against COVID-19. However, few broad-spectrum antiviral drugs have been evaluated against COVID-19 in clinical trials, resulted in clinical recovery. In the current review, we summarize the possibility to use Zidovudine as antiviral drug and Candesartan as Angiotensin II Receptor Blocker (ARB) on the basis Zidovudine works as RNA reverse transcriptase inhibitor (RTI) and Candesartan as ARB, the receptors that bind to the spike protein (S-protein) present in the surface or coronavirus.
\end{abstract}

Keywords: Coronavirus; SARS-CoV-2; COVID-19; RTIs; ARB; ACE Inhibitors; Candesartan cilexetil; Zidovudine.

\section{Introduction}

SARS-CoV 2 belongs to the Coronaviridae family. It represents spike proteins on the outer surface of the virus. The virus contains a single-stranded RNA as a nucleic material Fig. 1. The severe acute respiratory syndrome coronavirus 2 (SARS-CoV2) causes acute lung injury (ALI) and acute respiratory distress syndrome (ARDS) which leads to pulmonary failure and results in fatality. The World Health Organization (WHO) has decided to consider COVID-19 a pandemic. SARS-CoV-2 owns a structure with spike proteins and expresses polyproteins, nucleoproteins, and membrane proteins, such as RNA polymerase, 3-chymotrypsin-like protease, papain-like protease, helicase, glycoprotein, and accessory proteins [1], [2]. The spike protein of SARS-CoV-2 embraces a 3-D structure in the Receptor Binding Domain (RBD) region to keep the van der Waals forces [3]. The 394glutamine residue in the RBD region of SARS-CoV-2 is recognized by the critical lysine 31 residue on the human ACE2 
receptor [4]. The full mechanism of pathogenicity of SARS-CoV-2 from attachment to replication is mentioned in Fig. 2.

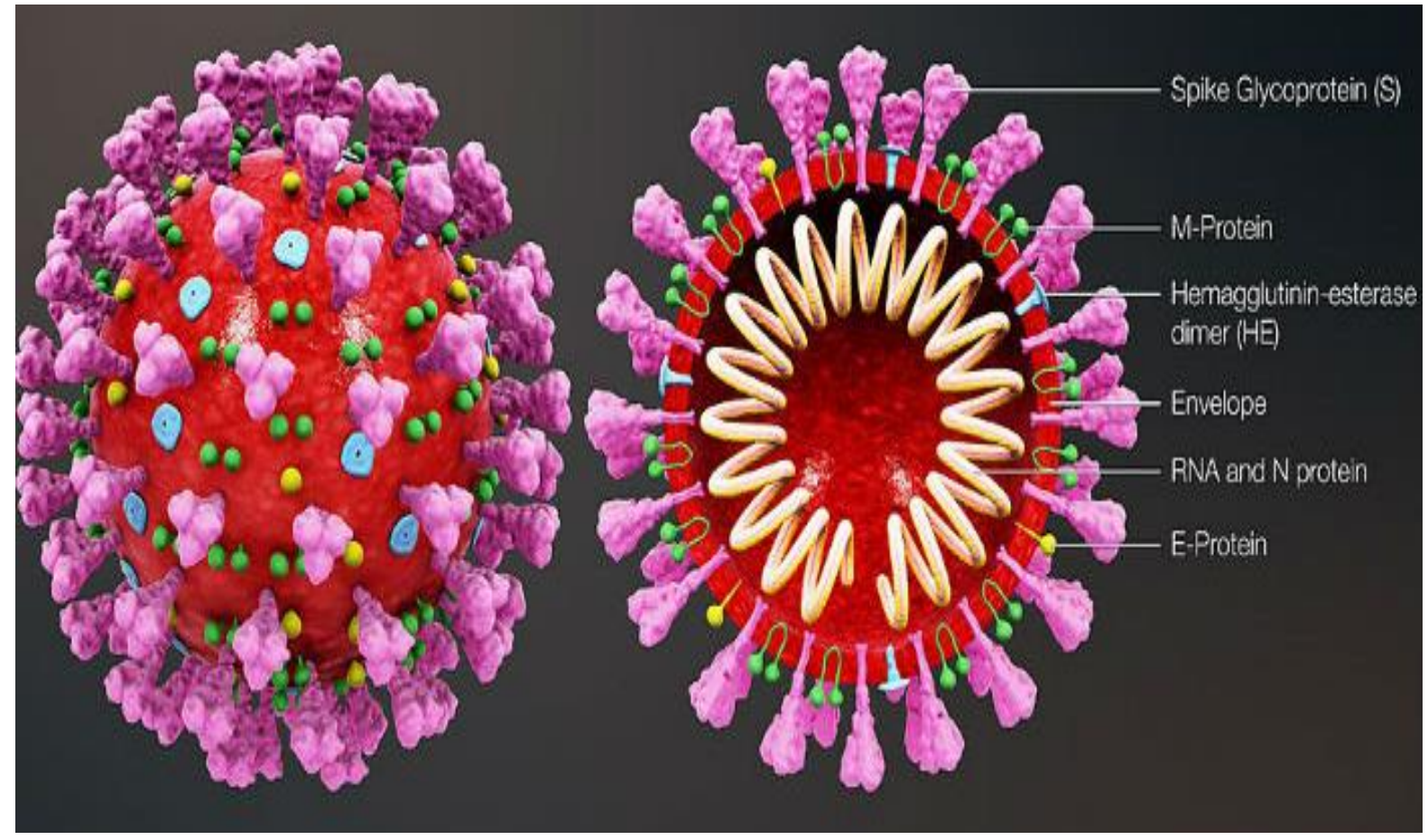

Figure 1. Structure of COVID-19 [5].

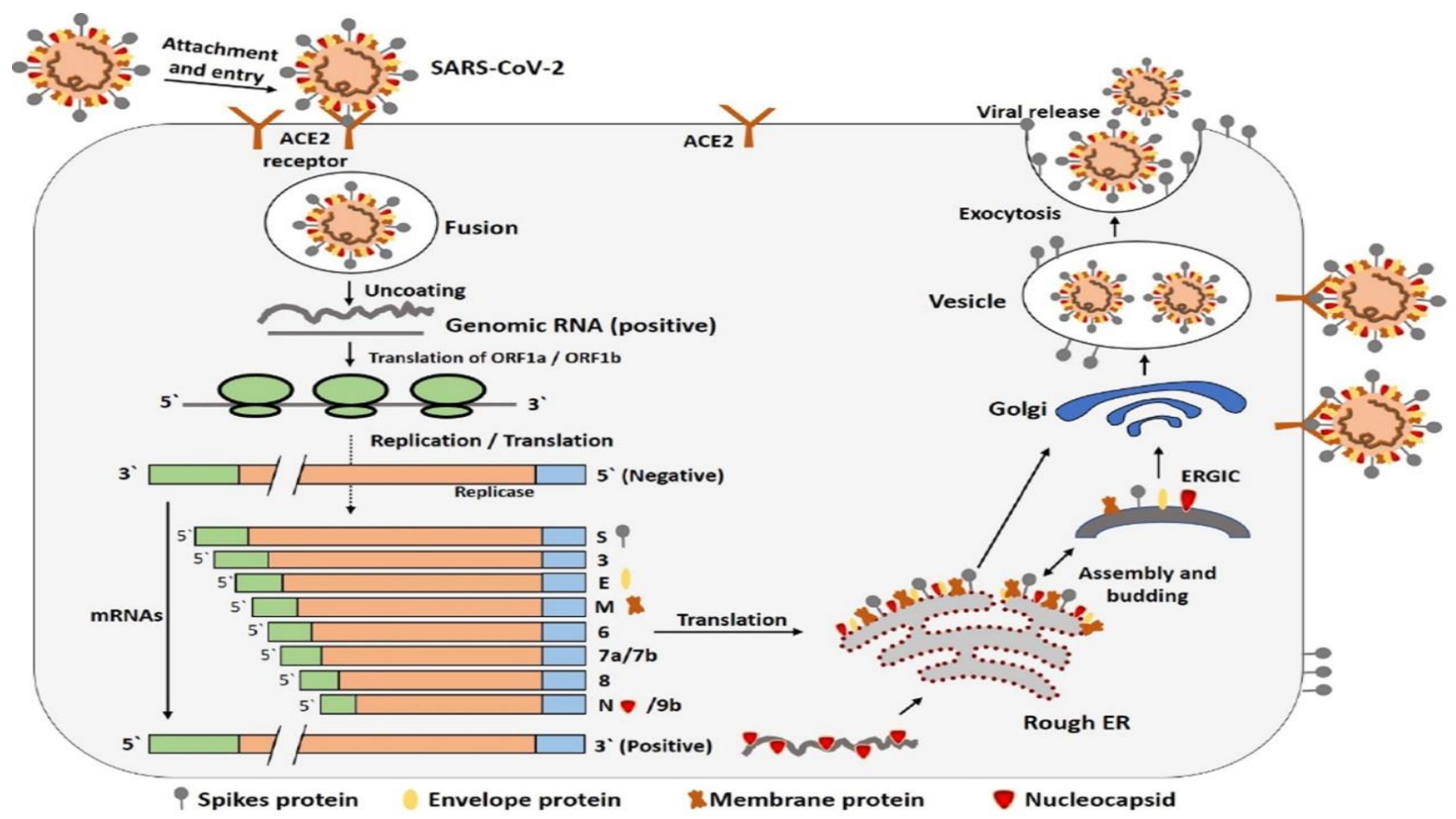

Figure 2. The life cycle of the SARS-CoV-2 in host cells. 
Zidovudine (ZDV), also known as azidothymidine (AZT), is an antiretroviral medication used to prevent and treat HIV/AIDS [6]. AZT is a thymidine analogue. AZT inhibits HIV's reverse transcriptase enzyme selectively, the enzyme used by the virus to produce a DNA copy from its positive sense single stranded RNA. Reverse transcription is essential for production of HIV's doublestranded DNA, which would be finally integrated into the genetic material of the infected cell [7], [8], [9]. AZT is converted to the effective 5'-triphosphate form by cellular enzymes. Studies have shown that the specific factor in the inhibitory effect is the termination of HIV's forming DNA chains [10].
Zidovudine mode of action is well mentioned in Fig. 3. COVID-19 mode of action in both transcription and replication, and using RTIs resembles that of HIV, thus theoretically zidovudine can be used as a trial drug for inhibition of COVID-19 transcription and replication pathways. M. Whirl-Carrillo, E.M. McDonagh, J. M. Hebert, L. Gong, K. Sangkuhl, C.F. Thorn, R.B. Altman and T.E. Klein. Candesartan cilexetil is a selective AT1 subtype Angiotensin II Receptor Antagonist (ARB) and Angiotensin II Converting Enzyme (ACE2) Inhibitor. Candesartan cilexetil medication prescribed for the treatment of hypertension in adults and in children 1 to $<17$ years of age, to lower the blood pressure after dose adjustment.

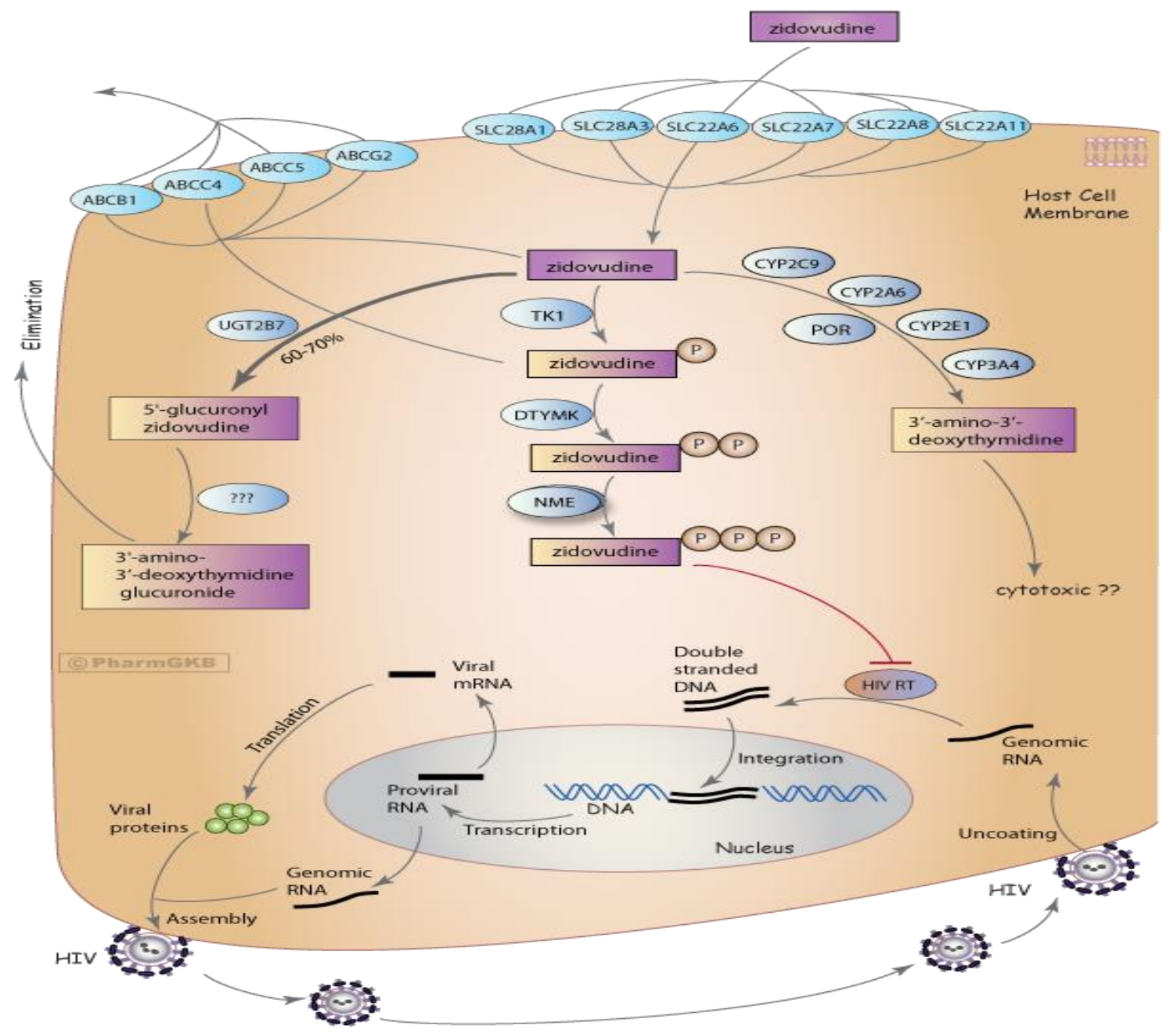

Figure 3. Mode of action of zidovudine in the host cell as reverse transcriptase inhibitor [11]. 


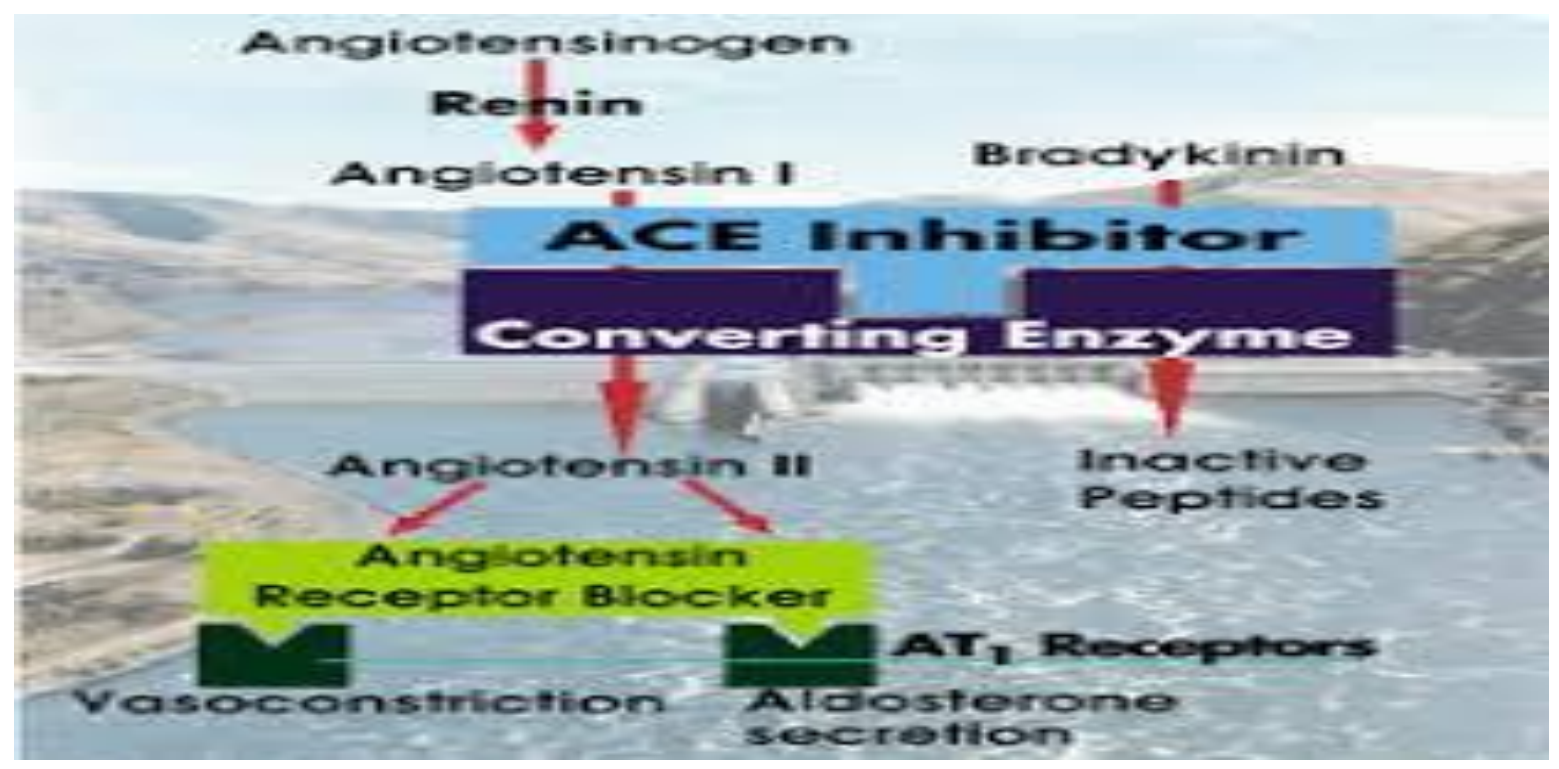

Figure 4. Mode of action of candesartan as ARB and ACE2 blocker.

It is AT1-receptor antagonist; that is, it blocks the activation of angiotensin. Blockage of AT1 receptors directly reduces secretion of vasopressin and reduces blood pressure. The entire mode of action of candesartan cilexetil is well mentioned in Fig. 4.

\section{Discussion}

SARS-CoV-2 life cycle starts when Sprotein already binds to the cell receptor ACE2. After receptor binding, the conformation alternate in the S-protein simplify viral envelope fusion with the cell membrane via the endosomal pathway. Thereafter SARS-CoV-2 liberates RNA into the host cell. Then RNA is translated into viral replicase polyproteins ( $\mathrm{pp} 1 \mathrm{a}$ and $1 \mathrm{ab})$, after that they are cleaved into small products by the viral proteinases. The polymerase produces a series of subgenomic mRNAs by way of discontinuous transcription and later translated into applicable viral proteins. Viral proteins and genome RNA are later assembled into virions in the Endoplasmic Reticulum (ER) and Golgi after which transported via vesicles and released out of the cell. SARS-CoV-2 begins invading into the body by binding to the host cell receptors, the same action which resemble candesartan cilexetil via the same pathway of Angiotensin II, thus candesartan cilexetil may inhibits this pathway, and furthermore candesartan cilexetil will act as Angiotensin II Receptor Blocker leading to interference with S-proteins at their site of binding. Hence the mechanism of action of candesartan cilexetil will lead to preventing or reducing the severity and ferocity of the symptoms of the disease caused by the transmission or infection with the virus such as ARDS or SARS-like symptoms. The study demonstrates a correlation between the activity of both Angiotensin II Receptor Blockers and Reverse Transcriptase Inhibitors towards the binding sites and RNA replication of coronavirus 2 respectively. Since zidovudine inhibits RNA Reverse Transcriptase Enzyme so it may prevent SARS-CoV-2 transcription and replication pathways. On the other hand, candesartan cilexetil which is ACE2 blocker and has ARB activity, it may prevent the binding of spike proteins of the virus to ACE2 receptors; therefore it can inhibit the entrance of the virus inside the host cell. We choose candesartan cilexetil particularly due to The advantages of candesartan over other ACE2 blockers and ARB medicines 
such as Losartan, Valsartan, Olmesartan, and Telmisartan are that of candesartan has high efficacy, high potency, a long duration of action, a highly selective compound to AT1 receptors, not associated with cough in patients with hypertension, and a tolerability outline is similar to placebo. These data support our expectations and hypothesis, also explain the significance of using these medications with little or absence of unexpected results such as side effects or contra-indications may related to Zidovudine or candesartan cilexetil, as the dose can be adjusted in children, elderly, during pregnancy, and lactation. Also, the mild hypotension that may results due to the anti-hypertensive effect of candesartan cilexetil can be monitored after adjusting its dose. The safety of these medications supports our explanations and making an argument for our position.

\section{Conclusion}

Zidovudine and candesartan cilexetil can be used each one alone or both together depending on the severity of the health condition of the patients to achieve maximum effectiveness in these patients with SARS-CoV-2 disease.

\section{Recommendation}

We suggest the use of these two medicines together for achieving synergism against the virus attacks. Using them as a trial drugs for treatment may be necessary in this critical time after revision by experts and primary care physicians in order to correct any identified inaccuracies or shortcomings and to ensure that the given data is relevant and concise to clinicians.

\section{Acknowledgement}

I would like to show my gratitude to my dear sister (Rasha A. Mostafa) for supporting and sharing her pearls of wisdom with me during writing this research.

\section{References}

1. F. Wu, S. Zhao, B. Yu, Y.M. Chen, W. Wang, Z.-G. Song, et al. A new coronavirus associated with human respiratory disease in China Nature., 15 (2020).

2. P. Zhou, X. Yang, X. Wang, B. Hu, L. Zhang, W. Zhang, et al.A pneumonia outbreak associated with a new coronavirus of probable bat origin Nature[Internet]., Feb (2020), p. 3.

3. Wong, S., Ting, Y., Chan, W., 2018. Epidemiology of non-alcoholic fatty liver disease-related hepatocellular carcinoma and its implications. JGH Open 2, 235-241.

4. X. Xu, P. Chen, J. Wang, J. Feng, H. Z hou, X. Li, et al. Evolution of the novel coronavirus from the ongoing Wuhan outbreak and modeling of its spike protein for risk of human transmission Science China Life Sciences., 63 (3) (2020), pp. 457-460.

5. https://www.thepharmaletter.com/articl e/china-s-scientists-unite-in-covid-19fight.

6. The American Society of HealthSystem Pharmacists. Archived from the original on December 21, 2016. Retrieved November 28, 2016. 
7. Mitsuya H, Weinhold K, Furman P, St Clair M, Li, Lars, Lehrman S, Gallo R, Bolognesi D, Barry D, Broder S (1985). "3'-Azido-3'-deoxythymidine (BW A509U): an antiviral agent that inhibits the infectivity and cytopathic effect of human T- lymphotropic virus type III/ lymphadenopathy-associated virus in vitro". Proc Natl Acad Sci USA. 82 (20): $\quad$ 7096-100. Bibcode:1985PNAS...82.7096M.

Doi:10.1073/pnas.82.20.7096. PMC 391317. PMID 2413459.innocent bystander, in: Seminars in Liver Disease. Thieme Medical Publishers, pp. 236-249.

8. Yarchoan R, Klecker R, Weinhold K, Markham P, Lyerly H, Durack D, Gelmann E, Lehrman S, Blum R, Barry D (1986). "Administration of 3'-azido3'-deoxythymidine, an inhibitor of HTLV-III/LAV replication, to patients with AIDS or AIDS - related complex". Lancet. 1 (8481): 575-80.

9. Mitsuya H, Yarchoan R, Broder S (1990). "Molecular targets for AIDS therapy". Science (Submitted manuscript). 249 (4976):153344. Bibcode:1990Sci...249.1533M..

10. Quan, Y; Rong, L; Liang, C; Wainberg, MA (1999). "Reverse Transcriptase Inhibitors Can Selectively Block the Synthesis of Differently Sized Viral DNA Transcripts in Cells Acutely Infected with Human Immunodeficiency Virus Type 1". Journal of Virology. 73 (8): 6700-6707.

11.https://www.pharmgkb.org/page/pathwayL egend 